\title{
ВАКЦИНЫ ПРОТИВ ГРИППА ЛОШАДЕЙ (обзор)
}

\author{
Л.В. КОСТИНА ${ }^{1}$, Т.В. ГРЕБЕННИКОВАํㅛ, А.Д. ЗАБЕРЕЖНЫЙ1, 2 , \\ Т.И. АЛИПЕР1, 2
}

Грипп лошадей - высокоинфекционное заболевание, характеризующееся тенденцией к быстрому распространению и высокой заболеваемостью среди чувствительного поголовья (К.П. Юров, 2009; S.P. Waghmare с соавт., 2010). Возбудитель гриппа лошадей - РНК-содержащий вирус, относящийся к семейству Orthomyxoviridae, роду Influenzavirus (Забережный А.Д. с соавт., 2017). На основании антигенных различий двух поверхностных гликопротеинов (НА и NA) выделяют два подтипа вируса гриппа лошадей (ВГЛ). Первый подтип (H7N7, equi-1), представленный прототипным штаммом A/equine/1/Prague/56, который впервые выделен в Чехословакии в 1956 году, менее вирулентный. Вспышки заболевания, вызванные им, не регистрируются с 1979 года. Второй подтип ВГЛ (Н3N8, еqui-2) циркулирует в большинстве стран мира, кроме Австралии, Новой Зеландии и Исландии, вызывая энзоотии в Америке и Европе (R. Paillot, 2014; B. Cowled с соавт., 2009; C.O. Perglione с соавт, 2016; A.I. Kydyrmanov c coaвт., 2009). Вакцинация против гриппа лошадей, наряду с карантинными и ограничительными мерами, служит одним из основных инструментов по контролю заболевания (S.S. Wong с соавт., 2013). Главная цель вакцинации - уменьшение проявления клинических симптомов заболевания и, как следствие, улучшение благополучия животных, что способствует сокращению периода реконвалесценции и снижению вероятности развития вторичных инфекций. Кроме того, вакцинация позволяет снизить выделение полевого вируса в окружающую среду и тем самым предотвращает распространение инфекции (D.J. Baker, 1986). Поскольку эффективность вакцинации против гриппа лошадей зависит от степени антигенной гомологии между вакцинными и циркулирующими штаммами вируса, вакцины должны включать актуальные циркулирующие штаммы ВГЛ, рекомендованные экспертной комиссией МЭБ (Международное эпизоотическое бюро, World Organisation for Animal Health, Франция) (OIE Expert Surveillance Panel on Equine Influenza Vaccine Composition, 2017; R. Paillot, 2014). C 2010 года МЭБ рекомендует включать в состав вакцин против гриппа лошадей репрезентативные штаммы ВГЛ подтипа Н3N8 сублиний Florida clade 1 (South Africa/03 или Ohio/03) и Florida clade 2 (Richmond/1/07). Включение штаммов подтипа H7N7 и H3N8 (европейской линии) не обязательно (R. Paillot, 2014; OIE Headquarters, 2017). B обзоре представлены актуальные данные по видам вакцин, используемых в практическом коневодстве. Среди них инактивированные цельновирионные, субъединичные, а также живые аттенуированные и векторные вакцины. Кроме того, приведены данные по разработке экспериментальных вакцин против гриппа лошадей, полученных с использованием современных генноинженерных методов. Рассмотрена технология обратной генетики вирусов гриппа, позволяющая усовершенствовать процесс получения прототипных вирусных штаммов для инактивированных и живых аттенуированных вакцин (Е.-J. Jung с соавт., 2010; E. Hoffmann с coaвт., 2010; Y. Uchida с соавт., 2014). Метод обратной генетики позволяет не только получать реассортантные вирусы гриппа, обладающие требуемыми антигенными свойствами и сниженной вирулентностью, но и дает возможность модифицировать их, следуя изменениям в антигенных свойствах циркулирующих полевых штаммов.

Ключевые слова: вирус гриппа лошадей, вакцинация, цельновирионные вакцины, субъединичные вакцины, аттенуированные вакцины, вакцины на основе векторов, рекомбинантные вакцины, методы обратной генетики.

Грипп лошадей - инфекционное заболевание лошадей, ослов и мулов, характеризующееся подъемом температуры тела до $41{ }^{\circ} \mathrm{C}$, катаром верхних дыхательных путей, болезненным сухим кашлем, ринотрахеитом, в тяжелых случаях пневмонией. Из других клинических признаков можно отметить миалгию, отсутствие аппетита и увеличение подчелюстных лимфатических узлов $(1,2)$. Смертность наблюдается в основном среди молодняка (жеребят, ослят) и ослов. У взрослых особей смертность, как правило, становится следствием общего болезненного состояния и/или вторичной бактериальной инфекции, ведущей к развитию плеврита и пневмонии (3).

Превентивные меры - это лучший способ предотвращения гриппозной инфекции, и вакцинация против гриппа лошадей остается важным 
инструментом контроля заболевания. В связи с этим крайне необходимо продолжать исследования, направленные на разработку новых и более эффективных вакцин. Единственная отечественная вакцина против гриппа лошадей, используемая в ветеринарной практике, относится к первому поколению инактивированных вакцин.

В настоящем обзоре представлена актуальная информация по вакцинации лошадей против гриппа, включая такие аспекты, как виды используемых и разрабатываемых вакцин. Сейчас существует множество технологий получения кандидатных вакцинных штаммов вируса гриппа, и одна из них - технология обратной генетики. С помощью этого метода впервые в России нами получен реассортантый штамм вируса гриппа recPR8-H3N8eq, который рассматривается в качестве кандидатного для создания вакцины против гриппа лошадей.

Возбудитель заболевания - РНК-содержащий вирус, относящийся к семейству Orthomyxoviridae, роду Influenzavirus (4). Тяжесть заболевания зависит от штамма вируса гриппа лошадей (ВГЛ) и иммунного статуса животных. На основании антигенных различий двух поверхностных гликопротеинов - гемагглютинина (HA) и нейраминидазы (NA) - выделяют два подтипа ВГЛ. Первый, менее вирулентный, подтип (H7N7, equi-1) представлен прототипным штаммом A/equine/1/Prague/56, впервые выделенным в Чехословакии в 1956 году. Последняя подтвержденная вспышка

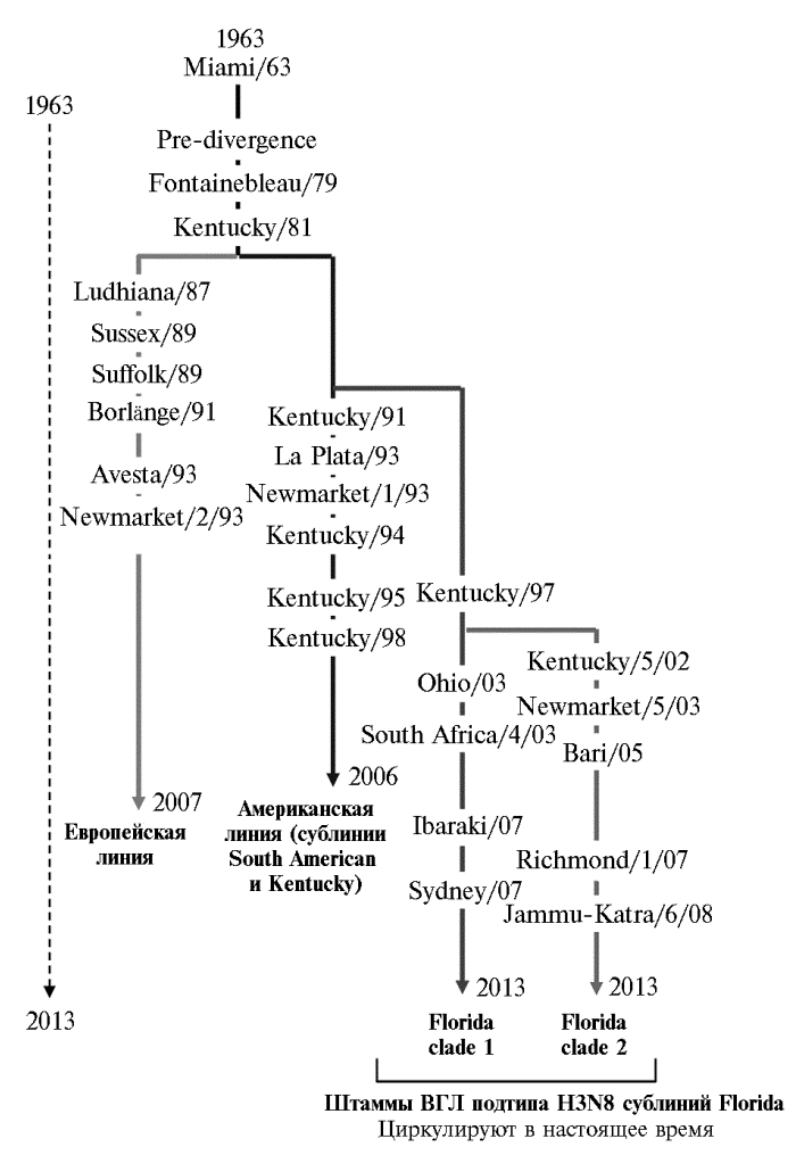

Схематическое изображение эволюции вируса гриппа лошадей (ВГЛ, основные сублинии и штаммы) (3). произошла в Италии в 1979 году, но вирус этого подтипа был выделен в Индии в 1987 году (5) и Египте в 1989 году (6). Второй подтип вируса (H3N8, еqui-2) представлен прототипным штаммом A/equine/2/Miami/63, который был выделен в Северной Америке в 1963 году (7). Он продолжает циркулировать в большинстве стран, кроме Австралии, Новой Зеландии и Исландии. С конца 1980-х годов ВГЛ Н3N8 подразделяют на американскую и европейскую линии (8). Внутри американской линии сформировались три сублинии с различными антигенными характеристиками - South American, Kentucky и Florida (9). В результате дальнейшей генетической эволюции внутри сублинии Florida образовались две группы вирусов (Florida clade 1 sublineage, Florida clade 2 sublineage), в которые входят все изоляты вируса, выделенные в последнее время в Америке (10, $11)$, Европе (12-14) и Азии $(15,16)$ (рис.). 
Следует отметить, что вакцины против гриппа лошадей разрабатывались и внедрялись в практику на протяжении 50 лет. Тем не менее ВГЛ подтипа H3N8 до сих пор вызывает энзоотии в Северной Америке и Европе. За последние 10 лет произошло несколько крупных вспышек гриппа среди лошадей в Швеции (2007 год), Австралии (2007 год) (17), Японии (2007 год) (18, 19), Индии (2008-2009 годы) (20), Южной Америке (2012 год) $(11,21)$, Казахстане (2007 год) (22), Монголии (2007-2008 годы) (23). В 2017 году в Китае (провинция Shandong) у ослов зарегистрирована вспышка гриппа, вызванная ВГЛ А/donkey/Shandong/1/2017(H3N8) (24). На территории Российской Федерации эпизоотии гриппа лошадей регистрировали в республиках Хакассия (2007 год), Бурятия и Тыва (2008-2009 годы) (25).

Вирусы гриппа А характеризуются значительной вариабельностью поверхностных гликопротеинов вириона (НА и NA). Следовательно, чем выше идентичность между генами $H A$ у вакцинного и полевого штаммов, тем эффективнее вакцинация снижает размножение вируса гриппа в респираторном тракте и его выделение в окружающую среду в случае заражения. Эффективная вакцина против гриппа лошадей должна включать актуальные циркулирующие штаммы ВГЛ (26).

Экспертная комиссия по вакцинам против гриппа лошадей Международного эпизоотического бюро (МЭБ, World Organisation for Animal Health - OIE, Франция) ежегодно предоставляет лабораторные и эпидемиологические данные о циркуляции штаммов ВГЛ, давая рекомендации по составу вакцин. С 2010 года МЭБ рекомендует включать в состав вакцин против гриппа лошадей репрезентативные штаммы ВГЛ подтипа H3N8 сублиний Florida clade 1 (South Africa/03 или Ohio/03) и Florida clade 2 (Richmond/1/07). Включение штаммов подтипа H7N7 и H3N8 (европейской линии) не обязательно $(3,27)$.

Вакцинация против гриппа лошадей (наряду с карантинными и ограничительными мерами) - один из основных инструментов по контролю заболевания (28). Основная цель вакцинации заключается в уменьшении проявления клинических симптомов заболевания и, как следствие, улучшении благополучия животных, что способствует сокращению периода реконвалесценции и снижению вероятности развития вторичных инфекций. Кроме того, вакцинация позволяет уменьшить выделение полевого вируса в окружающую среду, тем самым предотвращая распространение инфекции $(29,30)$. В Российской Федерации вакцинацию лошадей против гриппа регламентируют «Инструкция о мероприятиях по предупреждению и ликвидации заболевания лошадей гриппом» (утверждена Главным управлением ветеринарии Министерства сельского хозяйства СССР 1 сентября 1980 года) и «Ветеринарные правила перемещения спортивных лошадей по территории Российской Федерации» (утверждены Минсельхозом РФ 30.05.2003). Согласно этим документам, вакцинация против гриппа лошадей имеет рекомендательный характер. Профилактической вакцинации инактивированной поливалентной вакциной подлежат лошади, принадлежащие конным заводам, спортивным обществам и циркам; спортивные и племенные лошади, направляемые за пределы хозяйств; лошади из любых хозяйств при угрозе возникновения гриппа. Спортивные лошади, то есть лошади, имеющие паспорт Федерации конного спорта РФ (ФКСР) или Всероссийского НИИ коневодства (ВНИИК), а также цирковые и театральные лошади должны прививаться 1 раз в 6 мес.

Вакцины против гриппа лошадей, которые используются в настоящее время в ветеринарной практике, могут быть разделены в соответ- 
ствии с технологией изготовления на три группы: инактивированные цельновирионные/субъединичные, живые аттенуированные и векторные (табл.) (3).

Примеры используемых в практике вакцин против гриппа лошадей, классифицированные в соответствии с технологией изготовления (3)

\begin{tabular}{|c|c|c|c|c|}
\hline Название & $\begin{array}{l}\text { Фирма- } \\
\text { производитель }\end{array}$ & Адъювант & Антиген & Штаммы ВГЛ \\
\hline \multicolumn{5}{|c|}{$\begin{aligned} & \text { Инакти в и рованная } \text { цельнов } \\
&\end{aligned}$} \\
\hline DuvaxynTm IE Plus & «Elanco» (США) & Карбопол & $\begin{array}{l}\text { Цельные вирионы } \\
\text { ВГЛ }\end{array}$ & $\begin{array}{l}\text { Newmarket/1/93 (H3N8) Suf- } \\
\text { folk/89 (H3N8) } \\
\text { Prague/56 (H7N7) }\end{array}$ \\
\hline Calvenza ${ }^{\circledR}-03$ EIV & $\begin{array}{l}\text { «Boehringer Ingelheim } \\
\text { Animal Health» (Гер- } \\
\text { мания) }\end{array}$ & Карбопол & $\begin{array}{l}\text { Цельные вирионы } \\
\text { ВГЛ }\end{array}$ & $\begin{array}{l}\text { Newmarket/2/93 (H3N8) Ken- } \\
\text { tucky/2/95 (H3N8) Oiho/03 } \\
(\mathrm{H} 3 \mathrm{~N} 8)\end{array}$ \\
\hline $\begin{array}{l}\text { Equilis Prequenza } \\
\text { (обновлена в } 2013 \\
\text { году) }\end{array}$ & $\begin{array}{l}\text { «SSD Animal Health» } \\
\text { (CШA) }\end{array}$ & ISCOM-Matrix & $\begin{array}{l}\text { x Цельные вирионы } \\
\text { ВГЛ }\end{array}$ & $\begin{array}{l}\text { Newmarket/2/93 (H3N8) } \\
\text { South Africa/4/03 (H3N8) }\end{array}$ \\
\hline Equilis Prequenza & $\begin{array}{l}\text { «MSD Animal Health» } \\
\text { (США) }\end{array}$ & \multicolumn{2}{|c|}{ ISCOM-Matrix Субъединицы НA } & $\begin{array}{l}\text { Prague/56 (H7N7) } \\
\text { Newmarket/1/93 (H3N8) } \\
\text { Newmarket/2/93 (H3N8) }\end{array}$ \\
\hline EquipTM F & «Pfizer Ltd.» (США) & ISCOM & $\begin{array}{l}\text { Субъединицы НА } \\
\text { и NA }\end{array}$ & $\begin{array}{l}\text { Newmarket/77 (H7N7) Bor- } \\
\text { länge/91 (H3N8) } \\
\text { Kentucky/98 (H3N8) }\end{array}$ \\
\hline $\begin{array}{l}\text { Вакцина против } \\
\text { гриппа лошадей } \\
\text { инактивированная } \\
\text { поливалентная }\end{array}$ & $\begin{array}{l}\text { «Курская биофабрика» } \\
\text { (Россия) }\end{array}$ & $\begin{array}{l}\text { ॠидроокись } \\
\text { алюминия }\end{array}$ & $\begin{array}{l}\text { Цельные вирионы } \\
\text { ВГЛ }\end{array}$ & $\begin{array}{l}\text { Кэмбридж-63(H7N7) } \\
\text { Франция-98(H3N8) }\end{array}$ \\
\hline Flu Avert ${ }^{\circledR}$ I.N. & $\begin{array}{l}\text { и в а я а т т е н у и р о } \\
\text { «Intervet/Schering- } \\
\text { Plough Animal Health» } \\
\text { (Нидерланды) }\end{array}$ & $\begin{array}{l}\text { ванная хо } \\
\text { Нет }\end{array}$ & $\begin{array}{l}\text { л о д о а д а п т и р } \\
\text { Цельные вирионы } \\
\text { ВГЛ }\end{array}$ & $\begin{array}{l}\text { о в а н н а я } \\
\text { Аттенуированный холодо- } \\
\text { адаптированный вирус Ken- } \\
\text { tucky/91 (H3N8) }\end{array}$ \\
\hline PROTEQ FLU & $\begin{array}{l}\text { «Merial Animal Health } \\
\text { Ltd.» (Франция) }\end{array}$ & $\begin{array}{l}\text { В е к т ор н } \\
\text { Карбомер }\end{array}$ & $\begin{array}{l}\text { a я } \\
\text { HA }\end{array}$ & $\begin{array}{l}\text { Ohio/03 (H3N8) } \\
\text { Newmarket/2/93 (H3N8) }\end{array}$ \\
\hline $\begin{array}{l}\text { PROTEQ FLU }{ }^{\mathrm{TM}} \\
\text { (обновлена в 2014) }\end{array}$ & $\begin{array}{l}\text { «Merial Animal Health } \\
\text { Ltd.» (Франция) }\end{array}$ & Карбомер & HA & $\begin{array}{l}\text { Ohio/03 (H3N8) } \\
\text { Richmond/1/07 (H3N8) }\end{array}$ \\
\hline
\end{tabular}

Первым поколением вакцин против гриппа лошадей, которые использовались в ветеринарии на протяжении десятилетий, были цельновирионные инактивированные вакцины с включением гидроокиси алюминия в качестве адъюванта (31). Основное достоинство этого типа вакцин - их безопасность из-за отсутствия репликации вируса и неспособности вызывать заболевание у лошадей (32). Иммунная защита, индуцируемая такими вакцинами, основана на стимуляции преимущественно гуморального ответа у лошадей. Цитотоксический клеточный иммунный ответ не формируется (33). Вырабатываются специфические антитела не только к вариабельным поверхностным антигенам (НА и NA), но и к более консервативным белкам ВГЛ (таким как NP или М), которые предположительно ответственны за перекрестную иммунную защиту (3). Гуморальный иммунитет при использовании инактивированных вакцин против гриппа лошадей не является длительным. Показано, что традиционная инактивированная вакцина стимулирует выработку короткоживущих (менее 100 сут) антител класса $\operatorname{IgG}(\mathrm{T})$, не способных фиксировать комплемент, в то время как при естественной инфекции вирусом гриппа лошадей прежде всего происходит выработка вирусоспецифических антител класса IgA, а также IgG2a и IgG2b. Как следствие, для формирования у лошадей иммунного ответа на срок 12 мес необходимо проводить их многократную вакцинацию (2 раза и более) (34).

Субъединичные вакцины против гриппа лошадей содержат очищенные вирусные белки (НА и/или NA). При этом в качестве адъюванта 
используют иммуностимулирующий комплекс ISCOM или ISCOM-Matrix. ISCOM представляет собой сферические структуры диаметром 35 нм, образующиеся за счет гидрофобного взаимодействия амфифильных молекул антигена (НА и/или NA) с холестеролом, фосфолипидами и сапонинами Quillaja. Полученные комплексы обладают более высокой иммуногенностью, чем исходные белки (35). Поскольку ISCOM представлен микрочастицами, они легко поглощаются макрофагами, где и происходит процессинг и презентация антигенов. Вакцины на основе ISCOM-Matrix обладают схожими характеристиками, но вирусные белки в них не входят в состав липидно-сапонинового комплекса (36). Показано, что использование инактивированных вакцин против гриппа лошадей, в которых в качестве адъюванта использовался карбопол, стимулировало выработку большего количества протективных антител (37).

За последние 15-20 лет появилось новое поколение вакцин против гриппа лошадей (см. табл. 1), которые стимулируют как гуморальный, так и клеточный иммунный ответ. Один видов из таких вакцин - живые аттенуированные вакцины, которые изготавливаются на основе температурочувствительных (ts) и холодоадаптированных (ca) штаммов. При этом вакцинные штаммы ВГЛ in vivo эффективно репродуцируется при субоптимальной $\left(25^{\circ} \mathrm{C}\right)$ температуре верхних дыхательных путей, в которых индуцируют локальный и системный иммунный ответ, но не реплицируются в нижних отделах респираторного тракта (при 38-39 $\left.{ }^{\circ} \mathrm{C}\right)$, где репликация вируса дикого типа обычно сопровождается развитием бронхитов, бронхиолитов, интерстициальной пневмонии и отека (33).

Первая интраназальная живая аттенуированная вакцина против гриппа лошадей (Flu Avert ${ }^{\circledR}$ I.N., «Heska Corporation») разработана и лицензирована в 1999 году в США. Холодоадаптированный вакцинный штамм, входящий в ее состав, был получен посредством серийных пассажей ВГЛ A/Equine/Kentucky/1/91 в куриных эмбрионах (КЭ) при пониженных температурах $\left(34{ }^{\circ} \mathrm{C}, 30^{\circ} \mathrm{C}, 28{ }^{\circ} \mathrm{C}\right.$ и $\left.26^{\circ} \mathrm{C}\right)$ (38). Показано, что однократная вакцинация пони защищала животных от клинического проявления заболевания на период 3-6 мес и более при контрольном заражении гомологичным вирусом дикого типа (39), а также гетерологичным ВГЛ подтипа H3N8 европейской линии в отсутствии высокого содержания противовирусных антител (40).

Наряду с достоинствами этого типа вакцин нельзя не отметить риск возможной реверсии вакцинного вируса или его реассортации с циркулирующим вирусом дикого типа в организме лошади и последующего появления новых патогенных вирусов. Тем не менее экспериментально показано, что на протяжении пяти прямых последовательных пассажей от лошади к лошади не наблюдается реверсии вакцинного са штамма ВГЛ, входящего в состав вакцины Flu Avert ${ }^{\circledR}$, к дикому типу, что свидетельствует о стабильности аттенуации и температурочувствительного фенотипа (40).

После крупной вспышки гриппа лошадей, вызванной подтипом ВГЛ H3N8 в Казахстане (2007 год), в сотрудничестве с научно-исследовательским институтом гриппа (НИИ гриппа, г. Санкт-Петербург) была разработана первая казахстанская живая модифицированная са вакцина против гриппа лошадей. С помощью методов классической генетической реассортации был получен вакцинный са штамм А/HK/Otar/6:2/2010, несущий гены, кодирующие поверхностные белки (HA, NA) дикого штамма A/equine/Otar/764/2007 (Н3N8, американская линия Florida, clade 2), и гены, кодирующие внутренние белки (PB2, PB1, PA, NP, M, NS) донора аттенуации - са штамма A/Hong Kong/1/68/162/35 (H3N2). На лошадях 
изучена безопасность и эффективность вакцины. В настоящее время проводятся полевые испытания в условиях коневодческих хозяйств Казахстана $(41,42)$.

Развитие в конце XX века технологий обратной генетики революционно изменило возможности создания прототипных вирусных штаммов для инактивированных и живых аттенуированных вакцин. Метод обратной генетики, примененный для вируса гриппа, позволяет достаточно быстро создавать вакцинные штаммы-кандидаты с любым необходимым подтипом НА или NA. Рекомбинантные вирусы получают посредством клонирования индивидуальных молекул кДНК, кодирующих 8 сегментов РНК вируса гриппа А, в специальную плазмиду. Затем плазмиды трансфицируют в клетки эукариот $(43,44)$. Метод обратной генетики позволяет не только получать реассортантные вирусы гриппа, обладающие требуемыми антигенными свойствами и сниженной вирулентностью, но и дает возможность модифицировать их, следуя изменениям в антигенных свойствах циркулирующих полевых штаммов. В ветеринарии с использованием этого метода были получены вакцинные штаммы-кандидаты против вируса гриппа свиней (45) и птицы $(33,46)$.

Вводя мутации в гены внутренних белков вируса, а также удаляя факторы вирулентности высокопатогенных вирусов гриппа, можно получать аттенуированные штаммы $(45,47)$. M. Quinlivan с соавт. (48) получили три рекомбинантных ВГЛ с делециями в гене NS1, которые были аттенуированы относительно дикого типа исходного ВГЛ А/eq/Kentucky/5/02 (H3N8) и не реплицировались в интерферон-компетентных клетках in vitro. При испытании рекомбинантных ВГЛ в качестве кандидатных вакцин было показано, что вакцинация лошадей мутантным вирусом NS1-126 обеспечивала клиническую защиту животных при заражении диким типом вируса. При этом у вакцинированных лошадей значительно снижалась степень проявления клинических признаков заболевания, а также сокращался период вирусовыделения по сравнению с контрольной группой животных (49).

В начале 2018 года L. Rodrigueza с соавт. (50) сообщили о разработке температурочувствительной (ts) живой аттенуированной вакцины против гриппа лошадей. С помощью метода обратной генетики в полимеразные гены $P B 1$ и $P$ В2 ВГЛ A/equine/Ohio/1/2003 H3N8 (Florida sub-lineage clade 1) были внесены мутации, ответственные за ts, ca и att фенотип донора аттенуации A/Ann Arbor/6/60 H2N2 человеческой живой аттенуированной вакцины FluMist («MedImmune», США). Полученный рекомбинантный вирус эффективно реплицировался при пониженной температуре $\left(33^{\circ} \mathrm{C}\right)$ и in vivo и in vitro имел фенотип, схожий с таковым в случае живой аттенуированной вакцины против гриппа лошадей Flu Avert ${ }^{\circledR}$. Однократное интраназальное введение рекомбинантного вируса обеспечивало защиту лошадей от контрольного заражения гомологичным вирусом дикого типа $(50,51)$.

Векторные вакцины получают посредством вставки необходимого гена определенного патогена вместе с набором регуляторных элементов в вирусные векторы. При этом вирусные антигены экспрессируются и синтезируются de novo в инфицированных клетках $(52,53)$.

Вакцина ProteqFlu ${ }^{\circledR}$ («Merial Ltd.», Франция) - единственная живая рекомбинантная векторная вакцина против гриппа лошадей, которая применяется в практическом коневодстве с 2003 года (33). В качестве вектора для экспрессии генов НА вирусов гриппа лошадей A/equine/Ohio/03 (H3N8) и A/equine/Richmond/1/07 (H3N8) в этой вакцине используется рекомбинантный вирус оспы канареек (Canarypox, ALVAC) $(54,55)$. Вак- 
цина безопасна, поскольку рекомбинантный вирус оспы канареек вызывает абортивную инфекцию в клетках млекопитающих (56). У привитых лошадей формируются гуморальный и клеточный иммунные ответы. У однократно вакцинированных пони отмечали значительное снижение клинических проявлений заболевания после контрольного заражения по сравнению с контрольной группой животных. Количество вируса, выделяемого в окружающую среду (но не длительность периода вирусовыделения), также существенно снижалось. После 2-кратной вакцинации с 35суточным интервалом протективный уровень вируснейтрализующих антител (IgGa и $\mathrm{IgGb}$ ) сохранялся в течение 4 мес. Следовательно, для формирования у лошадей защитного иммунного ответа продолжительностью 12 мес необходимо 3-кратное введение этой вакцины $(57,58)$.

G.R. Van de Walle c соавт. (59) создали рекомбинантный вакцинный вирусный вектор на основе абортивного штамма NYO3 вируса герпеса лошадей 1-го типа (EHV-1), экспрессирующий ген $H A$ ВГЛ A/eq/Ohio/03. После 2-кратной (с 5-недельным интервалом) иммунизации лошадей полученным рекомбинантным вирусом у животных обнаруживали специфические антитела против ВГЛ на протяжении 18 нед после второй иммунизации. Однако протективность потенциальной вакцины при экспериментальной инфекции ВГЛ, а также безопасность вирусного вектора авторы не исследовали (59).

Технология обратной генетики - современный и эффективный подход для получения вакцинных штаммов с заданными свойствами (60). В НИЦ эпидемиологии и микробиологии им. Н.Ф. Гамалеи Минздрава РФ также ведутся работы по получению рекомбинантных вирусов гриппа при помощи методов обратной генетики. Так, был получен реассортантый штамм вируса гриппа recPR8-H5N1, имеющий ген HA от высокопатогенного вируса гриппа птиц А/Курган/05/2005 (H5N1), выделенного на территории России. Исследованы репродуктивные, антигенные и вирулентные свойства реассортанта. Показано, что экспериментальная инактивированная эмульгированная вакцина, изготовленная в лаборатории на основе штамма recPR8-H5N1, защищает 1,5-месячных цыплят от контрольного заражения высокопатогенным вирусом А/Курган/05/2005 (H5N1) (46). В настоящее время здесь в лаборатории молекулярной диагностики с целью разработки вакцины против гриппа лошадей ведутся исследования по получению реассортантного штамма ВГЛ, в котором гены $H A$ и $N A$ взяты от ВГЛ А/лошадь 2/Битца/07 (Н3N8), а остальные гены - от высокопродуктивного штамма A/Puerto Rico/8/34 (H1N1).

Таким образом, грипп лошадей - высокоинфекционное заболевание, характеризующееся тенденцией к быстрому распространению и высокой заболеваемостью среди чувствительного поголовья. Его вспышки могут значительно влиять на индустрию коневодства, особенно спортивного. Вакцинация против гриппа лошадей - эффективный инструмент по предотвращению болезни. Первым поколением вакцин были инактивированные цельновирионные и субъединичные вакцины, при использовании которых происходит выработка протективных антител. Впоследствии появилось второе поколение вакцин (живые аттенуированные и векторные), стимулирующих гуморальный и клеточный иммунный ответ и имитирующих протективный иммунный ответ, который возникает при естественной инфекции вирусом гриппа лошадей. Один из перспективных методов получения рекомбинантных живых аттенуированных вакцин - метод обратной генетики, с помощью которого можно получать реассортантные вирусы с требуемыми антигенными характеристиками, а также модифициро- 


\section{ЛИТЕРАТУРА}

1. Юров К.П. Грипп лошадей. Ветеринария, 2009, 6: 3-7.

2. Waghmare S.P., Mode S.G., Kolte A.Y., Babhulkar N., Vyavahare S.H., Patel A. Equine influenza: an overview. Veterinary World, 2010, 3(4): 194-197.

3. Paillot R. A systematic review of recent advances in equine influenza vaccination. Vaccines, 2014, 2(4): 797-831 (doi: 10.3390/vaccines2040797).

4. Забережный А.Д., Костина Л.В., Южаков А.Г., Гулюкина И.А., Степанова Т.В., Стаффорд В.В., Полякова И.В., Дроздова Е.И. Современная таксономия вирусов. Ветеринария и кормление, 2017, 1: 4.

5. Singh G. Characterization of A/eq-1 virus isolated during the equine influenza epidemic in India. Acta Virologica, 1994, 38(1): 25-26.

6. Ismail T.M., Sami A.M., Youssef H.M., Abou Zaid A.A. An outbreak of equine influenza type 1 in Egypt in 1989. Veterinary Medical Journal - Giza, 1990, 38(2): 195-206.

7. Waddell G.H., Teigland M.B., Sigel M.M. A new influenza virus associated with equine respiratory disease. J. Am. Vet. Med. Assoc., 1963, 143: 587-590.

8. Daly J.M., Lai A.C., Binns M.M., Chambers T.M., Barrandeguy M., Mumford J.A. Antigenic and genetic evolution of equine H3N8 influenza A viruses. Journal of General Virology, 1996, 77(4): 661-671 (doi: 10.1099/0022-1317-77-4-66).

9. Lai A.C., Chambers T.M., Holland R.E. Jr., Morley P.S., Haines D.M., Townsend H.G., Barrandeguy M. Diverged evolution of recent equine-2 influenza (H3N8) viruses in the Western Hemisphere. Arch. Virol., 2001, 146(6): 1063-1074 (doi: 10.1007/s007050170106).

10. Юров К.П., Алексеенкова С.В., Юров Г.К., Иванов В.В. Генотипирование и филогенетический анализ вируса гриппа лошадей H3N8. Ветеринария, 2011, 6: 22-25.

11. Alves Beuttemmuller E., Woodward A., Rash A., Dos Santos Ferraz L.E., Fernandes Alfieri A., Alfieri A.A., Elton D. Characterisation of the epidemic strain of H3N8 equine influenza virus responsible for outbreaks in South America in 2012. Virology Journal, 2016, 13: 45 (doi: 10.1186/s12985-016-0503-9).

12. Woodward A.L., Rash A.S., Blinman D., Bowman S., Chambers T.M., Daly J.M., Damiani A., Joseph S., Lewis N., McCauley J.W., Medcalf L., Mumford J., Newton J.R., Tiwari A., Bryant N.A., Elton D.M. Development of a surveillance scheme for equine influenza in the UK and characterisation of viruses isolated in Europe, Dubai and the USA from 2010-2012. Veterinary Microbiology, 2014, 169(3-4): 113-127 (doi: 10.1016/j.vetmic.2013.11.039).

13. Rash A., Morton R., Woodward A., Maes O., McCauley J., Bryant N., Elton D. Evolution and divergence of H3N8 equine iinfluenza viruses circulating in the United Kingdom from 2013 to 2015. Pathogens, 2017, 6(1): 6 (doi: 10.3390/pathogens6010006).

14. Fougerolle S., Legrand L., Lecouturier F., Sailleau C., Paillot R., Hans A., Pronost S. Genetic evolution of equine influenza virus strains (H3N8) isolated in France from 1967 to 2015 and the implications of several potential pathogenic factors. Virology, 2017, 505: 210-217 (doi: 10.1016/j.virol.2017.02.003).

15. Yondon M., Heil G.L., Burks, J.P., Zayat B., Waltzek T.B., Jamiyan B.O., McKenzie P.P., Krueger W.S., Friary J.A., Gray G.C. Isolation and characterization of H3N8 equine influenza A virus associated with the 2011 epizootic in Mongolia. Influenza and Other Respiratory Viruses, 2013, 7(5): 659-665 (doi: 10.1111/irv.12069).

16. Qi T., Guo W., Huang W.Q., Li H.M., Zhao L.P., Dai L.L., He N., Hao X.F., Xiang W.H. Genetic evolution of equine influenza viruses isolated in China. Archives of Virology, 2010, 155(9): 1425-1432 (doi: 10.1007/s00705-010-0724-y).

17. Cowled B., Ward M.P., Hamilton S., Garner G. The equine influenza epidemic in Australia: spatial and temporal descriptive analyses of a large propagating epidemic. Preventive Veterinary Medicine, 2009, 92(1-2): 60-70 (doi: 10.1016/j.prevetmed.2009.08.006).

18. Yamanaka T., Niwa H., Tsujimura K., Kondo T., Matsumura T. Epidemic of equine influenza among vaccinated racehorses in Japan in 2007. Journal of Veterinary Medical Science, 2008, 70(6): 623-625 (doi: 10.1292/jvms.70.623).

19. Ito M., Nagai M., Hayakawa Y., Komae H., Murakami N., Yotsuya S., Asakura S., Sakoda Y., Kida H. Genetic analyses of an H3N8 influenza virus isolate, causative strain of the outbreak of equine influenza at the Kanazawa racecourse in Japan in 2007. Journal of Veterinary Medical Science, 2008, 70(9): 899-906 (doi: 10.1292/jvms.70.899).

20. Virmani N., Bera B.C., Singh B.K., Shanmugasundaram K., Gulati B.R., Barua S., Vaid R.K., Gupta A.K., Singh R.K. Equine influenza outbreak in India (2008-09): Virus isolation, seroepidemiology and phylogenetic analysis of HA gene. Veterinary Microbiology, 2010, 143(2-4): 224-237 (doi: 10.1016/j.vetmic.2009.12.007). 
21. Perglione C.O., Gildea S., Rimondi A., Mico S., Vissani A., Carossino M., Cullinane A., Barrandeguy $\mathrm{M}$. Epidemiological and virological findings during multiple outbreaks of equine influenza in South America in 2012. Influenza and Other Respiratory Viruses, 2016, 10(1): 37-46 (doi: 10.1111/irv.12349).

22. Kydyrmanov A.I., Kumekbayeva Zh.Zh., Karamendin K.O., Daulbayeva K.D., Shakhvorostova L.I., Zhumatov K.Kh. Isolation of an influenza virus A (H3N8) from horses in Kazakhstan in 2007. Veterinarya, 2009, 5: 52-54.

23. Yondon M., Heil G.L., Burks, J.P., Zayat B., Waltzek T.B., Jamiyan B.O., McKenzie P.P., Krueger W.S., Friary J.A., Gray G.C. Isolation and characterization of H3N8 equine influenza A virus associated with the 2011 epizootic in Mongolia. Influenza and Other Respiratory Viruses, 2013, 7(5): 659-665 (doi: 10.1111/irv.12069).

24. Yang H., Xiao Y., Meng F., Sun F., Chen M., Cheng Z., Chen Y., Liu S., Chen H. Emergence of H3N8 equine influenza virus in donkeys in China in 2017. Veterinary Microbiology, 2018, 214: 1-6 (doi: 10.1016/j.vetmic.2017.11.033).

25. Сарыглар Л.К., Коломыцев А.А., Смирнов В.Н., Куулар Р.К., Достай С.М., Муруева Г.Б. Эпизоотический процесс гриппа лошадей в Бурятии и Тыве в 2008 г., обусловленный вирусом гриппа подтипов Н7 и Н3. Ветеринарная патология, 2009, 4: 41-46.

26. OIE. Chapter 2.5.7 Equine influenza. In manual of diagnostic tests and vaccines for terrestrial animals. OIE, Paris, 2016: 1-16. Режим доступа: http://www.oie.int/fileadmin/Home/eng/Health_standards/tahm/3.05.07_EQ_INF.pdf. Дата обращения 15.04.2019.

27. OIE Expert surveillance panel on equine influenza vaccine composition, OIE Headquarters, 28 March 2018. The World Organisation for Animal Health (OIE), 2017: 86-87. Режим доступа: http://www.oie.int/en/our-scientific-expertise/specific-information-and-recommendations/equine-influenza/. Без даты.

28. Wong S.S., Webby R.J. Traditional and new influenza vaccines. Clinical Microbiology Reviews, 2013, 26: 476-492 (doi: 10.1128/CMR.00097-12).

29. Baker D.J. Rationale for the use of influenza vaccines in horses and the importance of antigenic drift. Equine Veterinary Journal, 1986, 18(2): 93-96 (doi: 10.1111/j.2042-3306.1986.tb03554.x).

30. Palliot R., Pitel C.M., D’Ablon X., Pronost S. Equine vaccines: how, when and why? Report of the Vaccinology Session, French Equine Veterinarians Association, 2016, Reims. Vaccines, 2017, 5(4): 46 (doi: 10.3390/vaccines5040046).

31. Юров К.П., Жидков С.А. Испытание инактивированной вакцины против гриппа лошадей. Бюллетень Всесоюзного ордена Ленина научно-исследовательского института экспериментальной ветеринарии им. Я.Р. Коваленко, 1972, 14: 47-50.

32. Paillot R., Hannant D., Kydd J.H., Daly J.M. Vaccination against equine influenza: Quid novi? Vaccine, 2006, 24(19): 4047-4061 (doi: 10.1016/j.vaccine.2006.02.030).

33. Paillot R., Prowse L., Montesso F., Huang C.M., Barnes H., Escala J. Whole inactivated equine influenza vaccine: efficacy against a representative clade 2 equine influenza virus, IFNgamma synthesis and duration of humoral immunity. Vet. Microbiol., 2013, 162: 396-407 (doi: 10.1016/j.vetmic.2012.10.019).

34. Nelson K.M., Schram B.R., McGrergor M.W., Sheoran A.S., Olsen C.W., Lunn D.P. Local and systemic isotype-specific antibody responses to equine influenza virus infection versus conventional vaccination. Vaccine, 1998, 16(13): 1306-1313 (doi: 10.1016/S0264-410X(98)00009-7).

35. Исаенко Е.Ю., Бабич Е.М., Елисеева И.В., Ждамарова Л.А., Белозерский В.И., Колпак С.А. Адъюванты в современной вакцинологии. Annals of Mechnikov Institute, 2013, 4: $5-21$.

36. Elton D., Bryant N. HBLB's advances in equine veterinary science and practice. Facing the threat of equine influenza. Equine Veterinary Journal, 2011, 43(3): 250-258.

37. Holmes M.A., Townsend H.G., Kohler A.K., Hussey S., Breathnach C., Barnett C., Holland R., Lunn D.P. Immune responses to commercial equine vaccines against equine herpesvirus-1, equine influenza virus, eastern equine encephalomyelitis, and tetanus. Veterinary Immunology and Immunopathology, 2006, 111(1-2): 67-80 (doi: 10.1016/j.vetimm.2006.01.010).

38. Youngner J.S., Whitaker-Dowling P., Chambers T.M., Rushlow K.E., Sebring R. Derivation and characterization of a live attenuated equine influenza vaccine virus. American Journal of Veterinary Research, 2001, 62(8): 1290-1294.

39. Lunn D.P., Hussey S., Sebing R., Rushlow K.E., Radecki S.V., Whitaker-Dowling P., Youngner J.S., Chambers T.M., Holland Jr. R.E., Horohov D.W. Safety, efficacy and immunogenicity of a modified-live equine influenza virus vaccine in ponies after induction of exerciseinduced immunosuppression. Journal of the American Veterinary Medical Association, 2001, 218(6): 900-906 (doi: 10.2460/javma.2001.218.900).

40. Chambers T.M., Holland R.E., Tudor L.R., Townsend H.G.G., Cook A., Bogdan J., Lunn D.P., Hussey S., Whitaker-Dowling P., Youngner J. S., Sebring R.W., Penner S.J., Stiegler G.L. A new modified live equine influenza virus vaccine: phenotypic stability, restricted spread and efficacy against heterologous virus challenge. Equine Veterinary Journal, 2001, 33(7): 630-636 (doi: 10.2746/042516401776249291). 
41. Chervyakova O., Strochkov V., Tailakova E., Sultankulova K., Sandybayev N., Sansyzbay A., Gorev N., Sergeeva M., Potapchuk M., Repko I., Tsybalova L., Kiselev O. Recombinant strain A/HK/Otar/6:2/2010 (H3N8) for development of a live intranasal equine influenza vaccine. Journal of Equine Veterinary Science, 2014, 34(6): 749-758 (doi: 10.1016/j.jevs.2014.01.003).

42. Tabynov K. A new safe and effective cold-adapted modified live equine influenza virus vaccine that enables the differentiation of infected from vaccinated animals. Microbiology Independent Research Journal, 2016, 3(1): 68-73 (doi: 10.18527/2500-2236-2016-3-1-68-73).

43. Hoffmann E., Neumann G., Kawaoka Y., Hobom G., Webster R.G. A DNA transfection system for generation of influenza A virus from eight plasmids. Proceedings of the National Academy of Sciences, 2000, 97(11): 6108-6113 (doi: 10.1073/pnas. 100133697).

44. Jung E.-J., Lee K.-H., Seong B.L. Reverse genetic platform for inactivated and live-attenuated influenza vaccine. Experimental \& Molecular Medicine, 2010, 42(2): 116-121 (doi: 10.3858/emm.2010.42.2.013).

45. Richt J.A., Lekcharoensuk P., Lager K.M., Vincent A.L., Loiacono C.M., Janke B.H., Wu W.H., Yoon K.J., Webby R.J., Solorzano A., Garcia-Sastre A. Vaccination of pigs against swine influenza viruses by using an NS1-truncated modified live-virus vaccine. Journal of Virology, 2006, 80(22): 11009-11018 (doi: 10.1128/JVI.00787-06).

46. Забережный А.Д., Гребенникова Т.В., Воркунова Г.К., Южаков А.Г., Костина Л.В., Норкина С.Н., Алипер Т.И., Непоклонов Е.А., Львов Д.К. Получение нового штаммареассортанта вируса гриппа А/H5N1 методом обратной генетики и анализ его биологических свойств. Вопросы вирусологии, 2014, 59(6): 23-27.

47. Uchida Y., Takemae N., Saito T. Application of reverse genetics for producing attenuated vaccine strains against highly pathogenic avian influenza viruses. Journal of Veterinary Medical Science, 2014, 76(8): 1111-1117 (doi: 10.1292/jvms.13-062).

48. Quinlivan M., Zamarin D., Garcia-Sastre A., Cullinane A., Chambers T., Palese P. Attenuation of equine influenza viruses through truncations of the NS1 protein. Journal of Virology, 2005, 79(13): 8431-8439 (doi: 10.1128/JVI.79.13.8431-8439.2005).

49. Chambers T.M., Quinlivan M., Sturgill T., Cullinane A., Horohov D.W., Zamarin D., Arkins S., Garcia-Sastre A., Palese P. Influenza A viruses with truncated NS1 as modified live virus vaccines: Pilot studies of safety and efficacy in horses. Equine Veterinary Journal, 2009, 41(1): 87-92 (doi: 10.2746/042516408X371937).

50. Rodrigueza L., Reedyb S., Nogalesa A., Murciac P.R., Chambersb T.M., Martinez-Sobridoa L. Development of a novel equine influenza virus live-attenuated vaccine. Virology, 2018, 516: 7685 (doi: 10.1016/j.virol.2018.01.005).

51. Baz M., Paskel M., Matsuoka Y., Zengel J., Cheng X., Treanor J.J., Jin H., Subbarao K. A live attenuated equine H3N8 influenza vaccine is highly immunogenic and efficacious in mice and ferrets. Journal of Virology, 2015, 89: 1652-1659 (doi: 10.1128/JVI.02449-14).

52. Draper S.J., Heeney J.L. Viruses as vaccine vectors for infectious diseases and cancer. Nature Reviews Microbiology, 2010, 8(1): 62-73 (doi: 10.1038/nrmicro2240).

53. Breathnach C.C., Clark H.J., Clark R.C., Olsen C.W., Townsend H.G., Lunn D.P. Immunization with recombinant modified vaccinia Ankara (rMVA) constructs encoding the HA or NP gene protects ponies from equine influenza virus challenge. Vaccine, 2006, 24: 1180-1190 (doi: 10.1016/j.vaccine.2005.08.091).

54. Paillot R., Rash N., Garrett D., Prowse-Davis L., Montesso F., Cullinane A., Lemaitre L., Thibault J.-C., Wittreck S., Dancer A. How to meet the last OIE expert surveillance panel recommendations on equine influenza (EI) vaccine composition: a review of the process required for the recombinant Canarypox-based EI vaccine. Pathogens, 2016, 5(4): 64 (doi: 10.3390/pathogens5040064).

55. Paillot R., El-Hage C.M. The use of a recombinant canarypox-based equine influenza vaccine during the 2007 Australian outbreak: a systematic review and summary. Pathogens, 2016, 5(2): 42 (doi: 10.3390/pathogens5020042).

56. Poulet H., Minke J., Pardo M. C., Juillard V., Nordgren B., Audonnet J.-C. Development and registration of recombinant veterinary vaccines. The example of the canarypox vector platform. Vaccine, 2007, 25(30): 5606-5612 (doi: 10.1016/j.vaccine.2006.11.066).

57. Minke J.M., Toulemonde C.E., Coupier H., Guigal P.M., Dinic S., Sindle T., Jessett D., Black L., Bublot M., Pardo M.C., Audonnet J.C. Efficacy of a canarypox-vectored recombinant vaccine expressing the hemagglutinin gene of equine influenza $\mathrm{H} 3 \mathrm{~N} 8$ virus in the protection of ponies from viral challenge. American Journal of Veterinary Research, 2007, 68(2): 213-219 (doi: 10.2460/ajvr.68.2.213).

58. Soboll G., Hussey S.B., Minke J.M., Landolt G.A., Hunter J.S., Jagannatha S., Lunn D.P. Onset and duration of immunity to equine influenza virus resulting from canarypox-vectored (ALVAC®) vaccination. Veterinary Immunology and Immunopathology, 2010, 135(1-2): 100-107 (doi: 10.1016/j.vetimm.2009.11.007).

59. Van de Walle G.R., May M.A., Peters S.T., Metzger S.M., Rosas C.T., Osterrieder N. A vectored equine herpesvirus type $1(\mathrm{EHV}-1)$ vaccine elicits protective immune responses against 
EHV-1 and H3N8 equine influenza virus. Vaccine, 2010, 28(4): 1048-1055 (doi: 10.1016/j.vaccine.2009.10.123).

60. Nogales A., Martínez-Sobrido L. Reverse genetics approaches for the development of influenza vaccines. Int. J. Mol. Sci., 2017, 18(1): 20 (doi: 10.3390/ijms18010020).

\author{
1ФГБУ Национальный исследовательский центр \\ эпидемиологии и микробиологии \\ им. почетного академика Н.Ф. Гамалеи Минздрава России, \\ 123098 Россия, г. Москва, ул. Гамалеи, 18, \\ e-mail: t_grebennikova@mail.ru, lvkostina@mail.ru $\bowtie$; \\ 2 ФГБНУУ ФНЦ Всероссийский НИИ экспериментальной \\ ветеринарии им. К.И. Скрябина и Я.Р. Коваленко РАН, \\ 109428 Россия, г. Москва, Рязанский просп., 24 к. 2, \\ e-mail: zaberezhny@mail.ru, aliper@narvac.com
}

Поступила в редакцию 21 июня 2018 года

Sel'skokhozyaistvennaya biologiya [Agricultural Biology], 2019, V. 54, № 2, pp. 216-226

\title{
VACCINES AGAINST EQUINE INFLUENZA (review)
}

\section{L.V. Kostina ${ }^{1}$, T.V. Grebennikova ${ }^{1}$, A.D. Zaberezhnyil, 2 , T.I. Aliper1, 2}

${ }^{1}$ Gamaleya National Research Centre for Epidemiology and Microbiology, Ministry of Health of the Russian Federation, 18, ul. Gamalei, Moscow, 123098 Russia, e-mail t_grebennikova@mail.ru, lvkostina@mail.ru ( $\square$ corresponding author);

${ }^{2}$ Federal Scientific Centre Skryabin and Kovalenko All-Russian Research Institute of Experimental Veterinary RAS, 24/2, Ryazanskii Prosp., Moscow, 109428 Russia, e-mail zaberezhny@mail.ru, aliper@narvac.com

ORCID:

Kostina L.V. orcid.org/0000-0002-9556-1454

Grebennikova T.V. orcid.org/0000-0002-6141-9361

The authors declare no conflict of interests

Received June 21, 2018

Zaberezhnyi A.D. orcid.org/0000-0001-7635-2596

Aliper T.I. orcid.org/0000-0002-5876-2425

doi: 10.15389/agrobiology.2019.2.216eng

Abstract

Equine influenza is a highly infectious disease that can rapidly spread and induce high morbidity in susceptible horse populations (K.P. Yurov, 2009; S.P. Waghmare et al., 2010). Equine influenza is caused by RNA viruses are belonged to the genus Influenzavirus $A$ of the family Orthomyxoviridae (A.D. Zaberezhnyi et al., 2017). Two different equine influenza virus (EIV) subtypes have been recognized based on antigenic properties of the envelope glycoproteins (HA and NA), the H7N7 subtype (equi-1) and the H3N8. The H7N7 subtype was first isolated in Czechoslovakia in 1956 (prototype strain: A/eq/Prague/1/56). The last confirmed outbreak occurred in 1979 in Italy. The H3N8 subtype of EIV is still circulating in the most countries of the world and has caused outbreaks of disease US and Europe (R. Paillot, 2014; B. Cowled et al., 2009; C.O. Perglione et al., 2016; A.I. Kydyrmanov et al., 200;). Vaccination is one of the most effective tools, alongside isolation, movement restriction and basic biosecurity measures, to prevent EIV infection or to limit its consequences (S.S. Wong et al., 2013). The main goal of vaccination against equine influenza is a significant reduction in clinical signs of disease, virus replication and shedding. Potent EIV vaccines reduce virus transmission and increase resistance to infection (D.J. Baker, 1986). Because of effectiveness EIV vaccines depends on antigenic homology between vaccines and circulates strains of EIV all equine influenza vaccines should contain epidemiologically relevant strains recommended by the OIE (OIE Expert Surveillance Panel on Equine Influenza Vaccine Composition, 2017; R. Paillot, 2014). In accordance with last OIE recommendations EIV vaccines should contain both clade 1 and clade 2 viruses of the Florida sublineage. Clade 1 continues to be represented by A/eq/South Africa/04/2003-like or A/eq/Ohio/2003-like viruses. Clade 2 continues to be represented by A/eq/Richmond/1/2007-like viruses. It is not necessary to include an H7N7 virus or an H3N8 virus of the Eurasian lineage in vaccines (R. Paillot, 2014; OIE Headquarters, 2017). This review gives actual data about the types of licensed vaccines against equine influenza. Whole inactivated/sub-unit, live-attenuated and viral-vector based vaccines are considered. Numerous experimental EIV vaccines developed with modern molecular biology technique have been reported. Reverse genetics techniques which provide a good tool for the generation of recombinant influenza viruses and develop both inactivated and live-attenuated influenza vaccines are also discussed (E.-J. Jung et al., 2010; E. Hoffmann et al., 2010; Y. Uchida et al., 2014). Reverse genetics allows generation of artificial recombinant influenza viruses and provides the possibility to rapidly and easily modify the antigenic characteristics of the vaccine strain by genetic manipulation.

Keywords: equine influenza, vaccines, vaccination, whole inactivated vaccines, sub-unit vaccines, live-attenuated vaccines, viral-vector based vaccines, recombinant vaccines, reverse genetics. 